Gut, 1974, 15, 799-800

\title{
A comparison of the accuracy of peritoneoscopy and liver biopsy in the diagnosis of cirrhosis
}

\author{
M. BRUGUERA, J. M. BORDAS, P. MAS, AND J. RODES \\ From the Liver Unit, Hospital Clinico Y Provincial, University of Barcelona, Spain
}

SUMmARY The accuracy of peritoneoscopy and liver biopsy in the diagnosis of hepatic cirrhosis was compared in 473 consecutive patients submitted to both procedures. One hundred and fifty-two of them had cirrhosis diagnosed by one or both methods. There was $73 \%$ agreement between the two procedures. 'Apparent' false-negative results were $17 \cdot 7 \%$ for peritoneoscopy and $9 \cdot 3 \%$ for liver biopsy. The incidence of false-negative results in the diagnosis of cirrhosis can be reduced by combining both procedures.

Peritoneoscopy and liver biopsy are two recognized methods of diagnosing hepatic cirrhosis but the comparative efficiency of the two methods has not been satisfactorily established. The incidence of false-negative biopsies in cirrhosis has been considerable in some series, but there is no report on the incidence of false-negative peritoneoscopies.

In this retrospective study the diagnostic accuracy and the percentages of false-negative findings for each of the two methods were analysed in 473 patients submitted to peritoneoscopy and liver biopsy in order to determine whether the combination of the two methods might be more useful than the performance of only one of them in patients suspected of having cirrhosis.

\section{Method}

A combined procedure including peritoneoscopy and one hepatic biopsy was performed in $\mathbf{4 7 3}$ consecutive patients suspected of liver disease. Peritoneoscopies were carried out under local anaesthesia by the same operator (J.M.B.) using Fourés and Sass-Wolf peritoneoscopes. Diagnosis of cirrhosis was made after the observation of a clearly nodular hepatic surface of higher than normal consistence, associated with collateral circulation of the round ligament. Peritoneoscopically guided biopsies were obtained with a Vim-Silverman-Francklin needle. Samples were immediately fixed in $4 \%$ formalin and then processed in the usual manner, stained with haematoxylin and eosin, Masson trichrome, and silver impregnation for reticulin. Slides were examined by

Received for publication 3 July 1974 . two of us (M.B. and P.M.) in close cooperation without knowledge of the clinical data and peritoneoscopic diagnosis.

A histological diagnosis of cirrhosis was made if one of the following features was present (Scheuer, 1973): nodular regeneration, fragmentation of the biopsy with fibrosis at the margins and wide postnecrotic collapse with an abnormal relationship between portal tracts and central veins, and evidence of active liver-cell hyperplasia.

In order to compare the findings by the two methods, only the cases diagnosed as cirrhosis by one or both procedures were selected. Necropsy was performed in 16 of these cases, confirming the diagnosis made.

\section{Results}

The combination of both methods yielded a diagnosis of cirrhosis in 152 out of the $\mathbf{4 7 3}$ patients examined. A positive histological and peritoneoscopic diagnosis was obtained in $111(73 \%)$, and in 41 cases only one of the two procedures yielded the diagnosis. In the remaining 321 patients cirrhosis was excluded after the examination.

Among the 41 cases in which a discrepancy was found, cirrhosis was diagnosed histologically in 27 and peritoneoscopically in 14 . Thus the total number of 'apparent' positive results of peritoneoscopy was $125(82.3 \%)$ and of liver biopsy $138(90 \cdot 7 \%)$. The percentage of 'apparent' false-negative results is $17 \cdot 7 \%$ for peritoneoscopy and $9.3 \%$ for liver biopsy. The aetiologies of the 152 cases of cirrhosis were cryptogenic 83 , alcoholic 64 , Wilson's disease two, idiophatic haemochromatosis one, Thorotrast one, 
and secondary biliary cirrhosis one. There was no difference in the proportion of cryptogenic and alcoholic cirrhosis in the three groups of patients, those with histological and peritoneoscopic diagnosis of cirrhosis and those with histological or peritoneoscopic diagnosis.

The table reports the endoscopic and histological

\begin{tabular}{|c|c|}
\hline Peritoneoscopy & Biopsy \\
\hline $\begin{array}{l}\text { Hepatic fibrosis } \ldots \ldots \ldots \ldots \ldots 26 \\
\text { Normal liver } \ldots \ldots \ldots \ldots \ldots \ldots 1\end{array}$ & $\begin{array}{l}\text { Chronic aggressive hepatitis } \ldots 3 \\
\text { Alcoholic hepatitis } \ldots \ldots \ldots \ldots 2 \\
\text { Submassive hepatic necrosis } \ldots 1 \\
\text { Normal liver ............ } \\
\text { Nonspecific reactive hepatitis } 1 \\
\text { Not diagnostic ............6 }\end{array}$ \\
\hline Total.......... & Total $\ldots \ldots \ldots \ldots \ldots \ldots 14$ \\
\hline
\end{tabular}

Table Diagnosis made at the time of examination in cases of false-negative diagnosis of cirrhosis by

peritoneoscopy and biopsy

diagnosis given at the time of examination in cases of 'apparent' false-negative diagnosis of cirrhosis. Diagnosis of hepatic fibrosis means an irregular but not a nodular surface.

\section{Discussion}

It should be stressed that in the absence of a final verification, laparotomy with wedge biopsy, or necropsy, in a series of patients submitted previously to peritoneoscopy and needle biopsy actually represents an important limitation for any investigation attempting a comparison of the diagnostic accuracy of both procedures. Since our findings could not be controlled by postmortem examination except in 16 cases $(10 \%)$, the percentage of false-negative results of the two methods remains unknown.

As far as we know the only studies comparing peritoneoscopy and liver biopsy have been those of Vido and Wildhirt (1969), Fritsch, Herms, Huth, Wetzels, and Hausamen (1972) and Gros (1973). In these reports no false-negative findings of peritoneoscopy are given since the selection of patients was made only by endoscopic criteria, and the accuracy of liver biopsy was surprisingly low. Vido and Wildhirt failed to establish the diagnosis of cirrhosis in $51 \%$ of their cases, Fritsch et al in $49 \%$, and Gros in $23 \%$ of the cases.

Other investigators have reported a high index of false-negative results in blind biopsies, particularly in cases of chronic aggressive hepatitis (Soloway,
Baggenstoss, Schoenfield, and Summerskill, 1971)and Scheuer (1970) has pointed out the difficulties encountered in the histological diagnosis of macronodular cirrhosis. However, the reliability of liver biopsy has been high in some studies. Postmortem liver biopsies yielded positive results in $100 \%$ of nutritional cirrhosis and in $96 \%$ of posthepatic and postnecrotic cirrhosis (Braunstein, 1956). Others have supported the view that liver biopsy is a good method of establishing a morphological diagnosis of cirrhosis (Baggenstoss, 1966; Wilber and Foulk, 1967).

In the present study a high accuracy of peritoneoscopy and liver biopsy is shown (82.3 and $90.7 \%$ respectively), but the combination of both methods has afforded a significant increase in positive results. Peritoneoscopy in experienced hands is a very safe and well tolerated procedure, allows controlled biopsies to be carried out minimizing the risks inherent in the biopsy itself, and may reveal malignancies developed over cirrhotic livers (Bordas, Bruguera, Gassull, Cinca, Teres, and Rodes, 1973). Thus, we considered that combined peritoneoscopy and biopsy should be incorporated into the diagnostic procedure in cases of suspected cirrhosis.

We are grateful to Dr Vicente Arroyo for his helpful advice. Requests for reprints should be addressed to Dr M. Bruguera, Liver Unit, Hospital Clínico Y Provincial, Barcelona.

\section{References}

Baggenstoss, A. H. (1966). Morphologic and etiologic diagnoses from hepatic biopsies without clinical data. Medicine (Baltimore), 45, 435-443.

Bordas, J. M., Bruguera, M., Gassull, M. A., Cinca, J., Teres, J., and Rodes, J. (1973). Valor de la exploración laparoscópica en el diagnóstico de los tumores malignos del hígado. Medicina clin. (Barcelona), 60, 674-676.

Braunstein, H. (1956). Needle biopsy of the liver in cirrhosis. Arch. Path., 62, 87-95.

Fritsch, W. P., Herms, W., Huth, F., Wetzels, E., and Hausamen, T. U. (1972). Die Wertigkeit von Laparoskopie und Leberpunktion für die Diagnostik chronischer hepatopathien. Dtsch. med. Wschr., 97, 1635-1637.

Gros, H. (1973). Laparoskopie oder perkutane leberbiopsie. Munch. med. Wschr., 115, 492-494.

Scheuer, P. J. (1970). Liver biopsy in the diagnosis of cirrhosis. Gut, 11, 275-278.

Scheuer, P. J. (1973). Liver Biopsy Interpretation, 2nd ed. Baillière Tindall, London.

Soloway, R. D., Baggenstoss, A. H., Schoenfield, L. J., and Summerskill, W. H. J. (1971). Observer error and sampling variability tested in evaluation of hepatitis and cirrhosis by liver biopsy. Amer. J. dig. Dis., 16, 1082-1086.

Vido, I., and Wildhirt, E. (1969). Korrelation des laparoskopischen und histologischen Befundes bei Chronischer Hepatitis und Leberzirrhose. Dtsch. med. Wschr., 94, 1633-1637.

Wilber, R. D., and Foulk, W. (1967). Percutaneous liver biopsy. Amer. med. Ass., 202, 147-149. 